\title{
Features of transformation and synthesis of national art of India in contemporary design
}

\author{
Smirnova Margarita ${ }^{1, *}$, Vasilenko Elena ${ }^{1}$ \\ ${ }^{1}$ K.G. Razumovsky Moscow State University of Technologies and Management (the First Cossack University), 109004, Moscow, \\ Russia
}

\begin{abstract}
The article examines the influence of the national culture of India on modern design. The reflection of ethnic features in different types of art is considered. At the present stage of design development it is important to preserve the age-old traditions of art and culture, synthesis with modern life, materials and technologies. In this regard, of particular interest is the national culture, formed under the influence of economic and geographical (crossing the most important migration and trade routes of Eurasia), climatic conditions, artistic traditions and ancient religious beliefs. Empirical, theoretical and analytical research methods are necessary for the study of ethnic style design. For better perception, the history of Indian culture, which is rich in ancient religious buildings and monuments of architecture, was studied. The heritage of folk culture is a contribution to the art of designing modern design. The study revealed that the ethnic (Indian) style in design, has undergone numerous changes in its development, United the traditions of different cultures. Born before our era, Indian art has transformed from laconic and elementary forms into exquisite and multifaceted with an abundance of a decorative pattern. The growing interest of modern society in ethnic design, national art of the East, and in particular India, gives new opportunities for designers to use the centuries-old heritage of these countries in their activities.
\end{abstract}

\section{Introduction}

In the era of technological progress in modern society, more and more people are turning to folk art and traditions. Analyzing this desire for the revival of national traditions and familiarity with the traditions of other countries, we see that the lack of study of the culture of a particular country prevents the development of design in this direction. Adaptation, transformation and synthesis of folk art in modern design are impossible without in-depth study of traditional art.

India is a great country that cannot be imagined without national culture. At the beginning of the XXI century, the Journey into the past continues, the projects of modern interiors with exquisite bronze and terracotta sculpture, with polished marble inlaid with precious stones are developed. In the interior "more than anywhere else, you need a unity of style that extends to the interior space and the objects that fill it" [4, p. 191]. Particular attention is drawn to the art of wood carving in the interior, which is infinitely varied in shape patterns where solar signs are intertwined with floral motifs and figures of animals and compete with Kashmiri shawls. India is characterized by an abundance of gold, polished bronze and stone, shiny and expensive fabrics (Fig. 1-2).

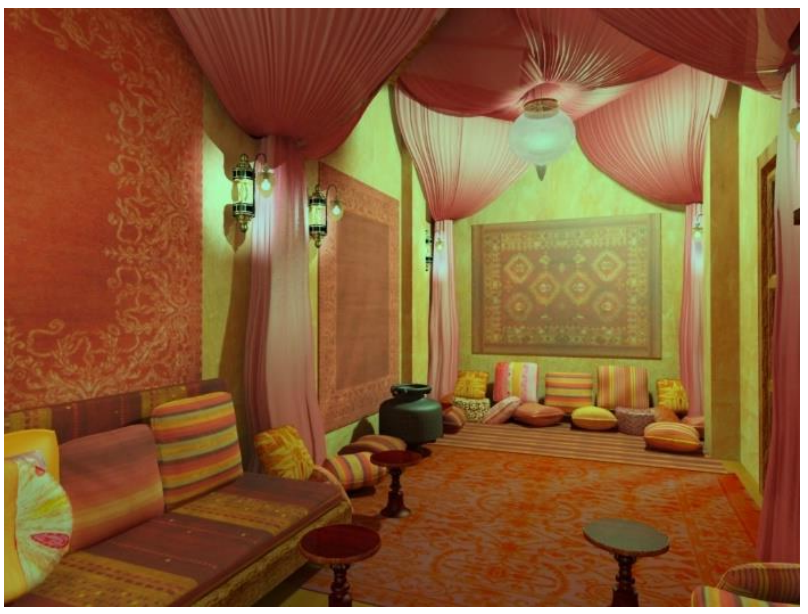

Figure 1. Carpets in the interior.

\footnotetext{
${ }^{*}$ Corresponding author: -45@bk.ru
} 


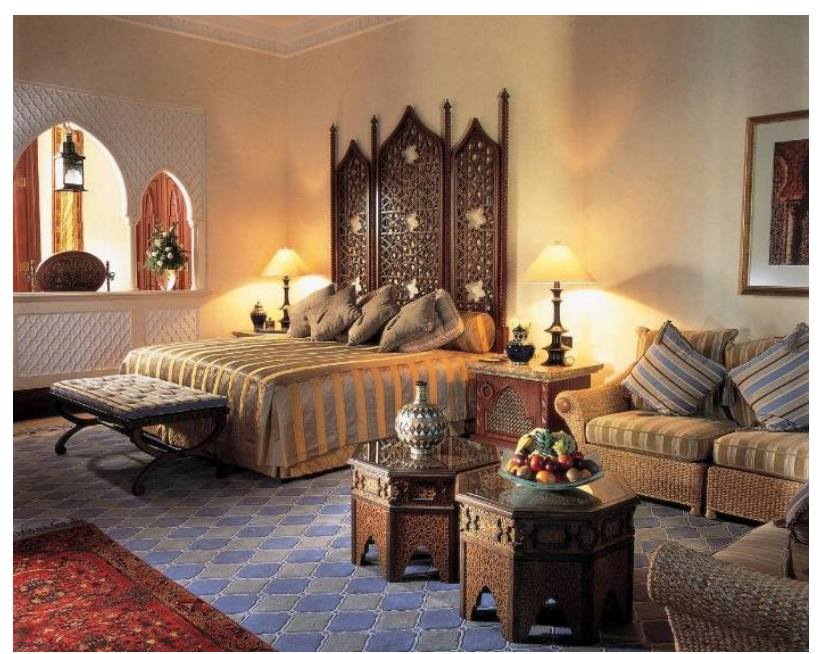

Figure 2. Wood carving in the interior.

It should be noted that the national culture is a Union of material and spiritual values of the ethnic group, as well as ethnic communities and ways of interaction between the environment and social groups. The modern understanding of the past culture is expressed by an increased interest in the ethno style, as this style was formed, assimilating with the existing external and internal cultural influences.

With the development of modern design there is a problem in finding new ideas. National culture of India, which has gone through the centuries-old history of the country, taking into account the influence of economic and geographical (the intersection of the most important migration and trade routes of Eurasia), natural and climatic conditions, artistic traditions and ancient religious beliefs. The possibility of using the ethnic component in the Indian style makes it possible for new design solutions in the design.

The purpose of the study is to preserve the age-old traditions of art and culture, synthesizing with modern life, materials and technologies. Examining the importance of ethnic characteristics and way of life in India, it can be noted that the cultural heritage of India, identity, has a great influence on the design of interior design in ethnic style, using national characteristics and principles and experience. Consideration of the culture of the country reveals its diversity and layering. Active implementation and interaction with modern technologies and materials enriches the modern world of interior design art. The importance of interaction between the national culture of India and design due to the preservation of the existing age-old traditions and perpetuating them through the material heritage. To reveal the purpose of the study of the national culture of India and the use of its heritage in the design, the following tasks are set:

1. The role of national tradition in the development of design.

2. Modern Indian style design.

3. Mutual influence and transformation of folk culture and design.

4. Synthesis of modern and traditional materials in Indian style design.
The national culture of India, being formed throughout its history, the ethnic groups of Indian civilization - is the history of different peoples, customs, religions, which, fighting and interacting, formed the phenomenon of Indian culture. Indian art traditions and crafts are diverse, they are inexhaustible. Its culture contains and reflects many customs, rich traditions, holidays.

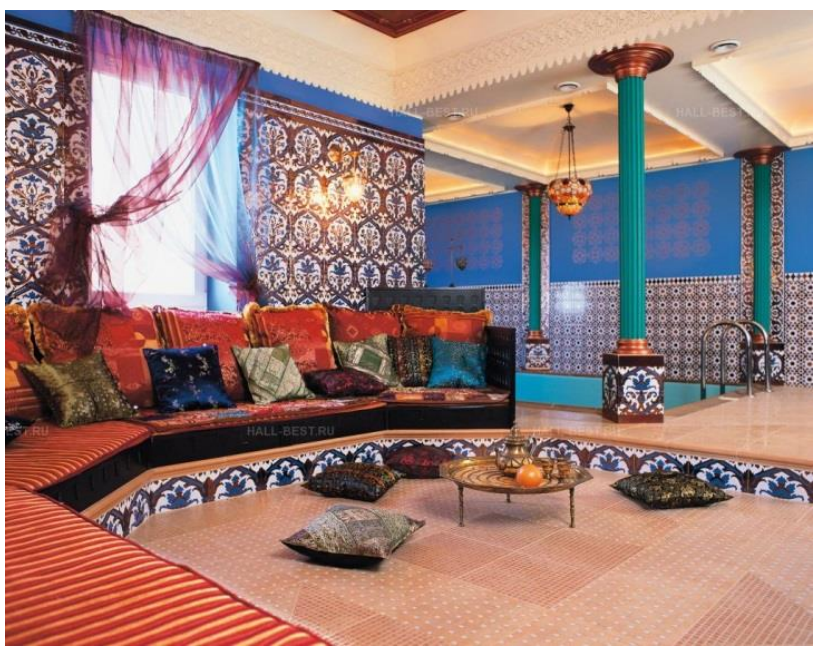

Figure 3. Exquisite luxury Indian interiors. Hall.

It combines the extreme asceticism of the yogis and the undisguised sensuality of Hinduism, Arab luxury (Fig. 3) and rough handicrafts, spiritual practices and household disorder, enlightenment and ignorance, wealth and poverty. Over several millennia, the traditions of different peoples mixed and intertwined, thus forming a unique pattern of multinational culture. This bold combination of diverse elements of national culture is observed in the interior, so that the Indian style easily and naturally fits into any, including European design. "Different countries use different national, folk themes to create the interior" [7, p. 126], and design in the Indian style is one of these areas.

"National culture is a synthesis of cultures of different classes, layers and groups, United by the unity of the territory, statehood and common economic life" [2]. The history of culture and fine arts of India dedicated to the works of M.F. Albedil, P.Y. Barannikova, A. Barth, L.B. Bhatt, A.L. Bashema, D. Weidemann, Y.V. Vasilkov, A.A. Vigasina, M.I. Vorobyova-Desyatovskaya, N.R. Guseva, T.Y. Elizarenkova, I.A. Ephraim B.I. Klyuev, V.S. Kostyuchenko, G.G. KotovskyKotovsky, M.P., J.F. Korchagov, I.Yu. Kotin, A.I. Krasnov, N. Krasnodebski, A.A. Kuzenkova,

"Any of the national cultures takes one of the leading places in this process, as it incorporates the facts of domestic and world material and spiritual culture, cultural realities of modernity and the past" [4, p. 207].

\section{Materials and methods}

To achieve the goal of studying the design of interior design in the ethnic style with Indian flavor, it is 
necessary to apply empirical, theoretical, analytical research methods. Empirical research methods "sensual" methods in science:

Observation, perception of cultural objects, in the course of which we gain knowledge about the external sides, properties. Collection of information about different types of art. Comparison is a method that reveals the similarity or difference of elements of fine art. The theoretical method of research involves the study of various sources of information about the cultural heritage of India. Analytical method - analysis of the obtained information about the color, which occupies a fundamental place in the culture of India; connection of natural associations with the laws of color perception in Indian culture; identification of the role of mythology and ethnosemantics in the color of applied art of the Indian people. The analytical method is necessary for the study of protodesign formation; ideological and semantic content in the culture of the East and the West and the disclosure of the role and importance of national culture: in festive clothes, in the objects of arts and crafts, small plastics, pottery, jewelry and other forms of national art. Synthesis - combining disparate elements into a single unit. We resort to this method to get a general idea of the application of ethnic design, taking into account the Indian component. This study examines the methodological component of cross-cultural relations between multinational India and modern developed countries that use design as a system of thinking in various fields, including industrial design, environment and interior design. Thus, Indian art traditions and crafts have both many directions and borrowings, especially from European countries. Given that this is the birthplace of Buddhism, this culture is based on the idea of a harmonious and balanced existence. "Folk culture is a traditional culture that includes cultural layers of different eras, the subject of which is the people - a collective personality, which means the Union of all individuals of the collective community of cultural ties and mechanisms of life. This culture is written-free, which is why it is of great important tradition as a way to broadcast vital information for society" [1].

\section{Discussion}

Exploring the design of such a colorful and ambiguous country as India, reveals the problem of the study, which is aimed at a more in-depth consideration of not only the historical and modern development of India, but also the growth of knowledge in the field of design and its impact on the development of the country and the links of world cultures.

India is a country where hundreds of people live. Its number exceeds 1 billion people. It is a country in which different religions are professed and customs are observed. All this contributes for the culture, shows the multi-layered way of life and special ideas about art. The study of national traditions allows you to make a lot of new European design, forming different styles in the interior. Popular in England colonial style is a European interior, enriched by Indian ethnic motifs. So elements of
Indian exotics were used in the interiors of art Nouveau and art Deco. Indian interior elements were transformed with each passing century, the process of its formation, he began with the idea of simplicity and functionality, and later in it there was a craving for elegance and originality. From simple and crude forms, the Indians moved to the embodiment of art itself, with multiple figured elements and hand patterns (Fig. 4).

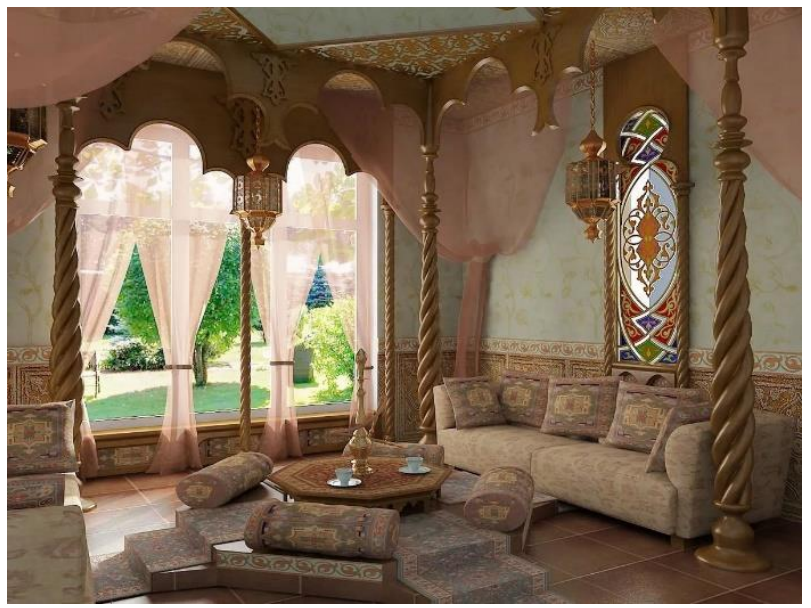

Figure 4. Living room interior.

Passion for yoga and various spiritual practices aroused interest in India in the second half of the twentieth century. This appeal to the origins enriched the reflection of the Indian way of life in various forms of art. Ethnic culture is reflected in the activities of the people and the state, in the traditions of the nation, its spiritual values, thinking, moral norms, in the interaction of ethnic and interpersonal relations, taking into account the semiotics of language, art, traditions and way of life. National culture, as well as ethnic culture, affects the life of society with its cultural value, affects the formation, development and formation of self-consciousness of modern man, contributes to the change of his mentality. "From the first days of his life, a person is included in a specific system of objective relations of people around him and reality, in the system of relationships between these people with each other and with himself, which has a pronounced national character" [6, p. 3]. One of the important functions of ethnic culture is the preservation of national cultural heritage as a unique phenomenon, the human environment, which is materialized and projected on the created objects. "The formation and development of modern design is influenced by such aspect as the organization of the space in which the unity of research and design is formed, significantly increasing the efficiency of activity and functioning of systems in the creative process" [7, p. 55]. Design affects both the external organization of space and the internal, personal space of a person. The manifestation of culture in design is indisputable and necessary, but, unfortunately, the presence and use of ethnic culture in modern interior design is reduced. Considering the interior in ethnic style with the use of Indian color, it is impossible not to note the riot of colors not only in the subject components, but everywhere. This characteristic feature can be traced in 
the exterior of some buildings and temples. The manifestation of national culture, its materialization, is a reflection of the artistic experience of many generations, affects the formation and acquisition of new experience in the field of design. Shaping and structure in interior design and individual objects are based on the forms used in the national art of India, so there is a fusion of modernity and ethnic style. The application of this experience in the design of art objects has not only artistic, but also practical significance. These art objects carry through the years the energy, uniqueness and originality of the technologies used, expressing the time in which they were created. Design and artistic activity design is associated with the development of the subject content of the interior. It is a connection with the system of information and visual communication, the organization of human life on a functional and rational basis [8]. Design is a product of culture, its tool, which actively forms new approaches and methods of creating an object, interpreting the previous culture in a different form, reflecting it in the new world. The emergence and development of design has had a significant impact on the formation of the modern multi-subject world, from painting to architecture, affecting in parallel all kinds of human activities, affecting the quality of knowledge and their use in practice. Many objects are now created for a short period of operation, taking into account only the economic component, thereby neglecting and sacrificing the artistic quality and concept. This is due to the fact that at the moment everyone is trying to buy and make the goods cheaper using cheap materials, creating from this not works of art taking into account their values but simply a product for use. Modern society has moved to a new stage - the society of consumers, which caused a change in attitude to creativity and art - art becomes an object of mass consumption. This object is replicated in large quantities with a low consumer price. Given the fact that a piece of art or design can exist for a long time, it should not be cheap, and cannot be designed cheaply, since "all elements of the composite solution of the project should be interconnected and designed in the same style" [10, p. 357].

Previous generations relied on the highest quality of performance of objects, thus left their mark in history, for example - many architectural monuments and religious buildings.

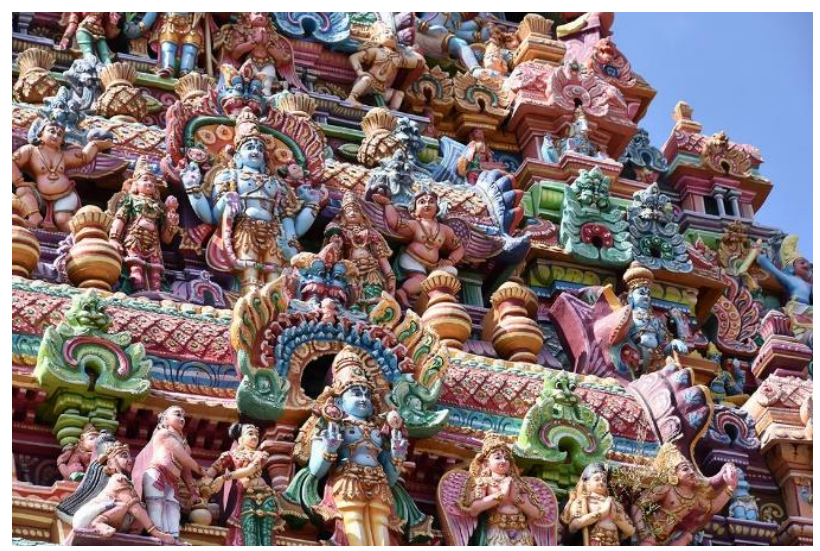

Figure. 5. A memorable sculpture of the Ranganatha temple.
Among the many architectural relics of India, a special place is the Hindu temple of Ranganatha complex, built in the 1 st century ad. It is a temple city, and its distinctive feature is a unique facade, decorated and dotted with incredible sculptures of deities that reflect the history and culture of the country (Fig. 5). These sculptures depicting various mythological heroes, deities, musicians, dancers, animals tell about any events and traditions, reflect Hindu philosophy. The whole view of the temple complex appears before the eyes of every visitor stunningly, because it consists of numerous pavilions, chapels and towers located on a huge territory and surrounded by majestic walls stretching for almost ten kilometers. The composition and decor of the painted sculptures of the temple is made in ethnic style, we can say that there can be traced a single concept of design according to the laws of monumental composition.

\section{Results}

The task of design is to serve not only material, but also spiritual and aesthetic needs of people, contributing to the expansion of the space of artistic development of various aspects of human life, the introduction of products of artistic and technical creativity in many areas of society [11]. Thus, it contributes to the formation and elevation of various aspects of human spiritual culture: aesthetic value orientations, artistic taste, humanization of socio-cultural relations, values of style and lifestyle.

The current trend of creating an object, thing, design of an art object, which is not long-term, affecting the culture of several generations, leads to leveling, erasing the distinctive features and differences of national characteristics. Unfortunately, the mentality of modern man is inherent to give preference to fast and cheap design, the subject, more profitable at the moment, so almost everything created, becomes exclusively commercial. Of course, modern capabilities, technology and materials, promote design to a new level, giving the opportunity to create new forms and use them in different ways. Many of the objects created in accordance with traditions, bringing their history, era, talking about the past, will be a valuable heritage for later ages. So occurring interchange, not only between cultural communities, but also between cultural layers, is directed on cognitive development of the personality [12, page 145]. Currently, Indian culture is one of the most recognizable. Bright and distinctive features of the Indian style inspire musicians, designers, artists around the world. All this is possible only due to the fact that the people of the country honors and remembers its history, religion, preserves traditions, absorbs and assimilates with the influence on it from the outside, but remains always true to its history and traditions. After all, this is "a unique perception of the world, the idea of beauty, and, of course, a unique national character" [12, p. 50]. It should be noted that ethnic design in the Indian style has a special place in the modern development of design, forming and developing new approaches and ideas of transformation and synthesis of folk art and modern design, taking into account the experience of its 
predecessors. This experience, being universal, influences the level of cultural achievements in the field of design all over the world.

\section{Conclusion}

Summing up, it is necessary to draw conclusions about the need to preserve and project national traditions in the design and interior design. The formation of the spiritual personality and its artistic taste is achievable by the spread of national culture in everyday life, taking into account the influence of cultural elements on modern reality. Images of ancient culture are manifested in the art and culture of modern civilization everywhere, applying the achievements of traditional culture which is the foundation for modern interior taking into account the traditions and experience of generations. This experience, accumulated over the centuries, develops using modern achievements, with the condition that the culture of the people cannot develop separately.

European design in the ethnic style, using the national art of the East, namely India, gives new opportunities to modern designers to use in the design activities of the centuries-old heritage of art in these countries. The synthesis of arts and crafts of such national culture as the culture of India, with its rich and diverse flavor, obliges designers to study the traditional art of this country. The popularization of ethnic style enriches the possibilities of modern design in all areas.

\section{References}

1. O.A. Belikova, A.V. Kotyshov. Planning of space and subject environment of the interior. In the book: teaching at the crossroads of epochs: innovation and tradition in the field of educational technology. 191194. (2017).

2. E.V. Vasilenko, P.G. Vasilenko. Using the values of folk art culture in the creation of modern works of art In the collection: Education. Science. Culture materials of the international scientific forum. 206208. (2018).
3. P.G. Vasilenko, E.V. Vasilenko. Decorative panel as a center of conceptual etching of interior design. In the collection: Education. Science. Culture materials of the international scientific forum. 125-127. (2018).

4. L.K. Vartanova. Origami as a method of creative expression. Methodological, theoretical and technological resource of information and educational environment. Moscow. 389-395. (2018).

5. E.V. Savelyeva. Project of introduction of ethnocultural component in the content of the educational process at the faculty of technology and entrepreneurship of MSPU. M.: MSPU, 36 (2008).

6. V.I. Kukenkov. The Culture of design and methodological aspects of space. Space of dialogues: art and design. The collective monograph. Sterlitamak. 54-73. (2017).

7. A.N. Lavrentiev. History of design: studies. benefit. M.: Gardariki, 303. (2007).

8. E.V. Lopasova. Formation of the aesthetic image of the urban environment by means of modern monumental art. In the collection: Modernization of humanitarian and artistic education: innovative development strategies Materials of the International scientific and practical conference: in 2 parts. Edited by: V.P. Gritsenko, I.V. Alexeyevoi, S.S. Zengin, A.A. Enikeeva. 354-361. (2014).

9. S.M. Mikhailov, L.M. Kulieva. Basis of design: a Textbook for specialty "Design of architectural environment". Kazan, (1999).

10. V.I. Kukenkov. Typology of interior space on the basis of cognitive activities in visual culture. Visual images of modern culture: secular and religious strategies of constructing the life-world. OSU, Omsk. 145-146. (2017).

11. M.A. Smirnova, M.E. Govorova. The Problem of preservation and revival of traditional folk crafts in our days. Space of dialogues: arts and crafts and design. The collective monograph. Ufa. 48-61. (2018). 